\title{
Qualidade do espaço e habitação humana
}

\section{Quality of space and human dwelling}

Jorge de Campos Valadares 1

\begin{abstract}
This study focuses on human housing, as a task involving constructing, inhabiting and understanding the world. This task starts with inventing one's own body, the first instrument for living and one's first dwelling place. Since humans are made up of memory and conviviality, daily space and time are essential to this task, to the reconstruction of nature. Man's house is first and foremost the place of presence and construction of histories. Alarm, which is essential to examine the situation of the subject, finds empty spaces, "nowhere lands", now infinitely multiplied, where subjects emerge, but where they can also get lost forever. We confirm, through the analysis of human housing, that there is no public health, but a collective health, to be continuously invented from new versions presented by subjects in the cultural scene.
\end{abstract}

Key words Space and Quality of Life; Subject's Situation; Subjectivity and Space
Resumo Pretendemos acompanhar aqui a evolução da habitação humana como uma tarefa de construir, habitar e compreender o mundo, iniciando pela invenção e habitação do próprio corpo, o primeiro instrumento de viver e a primeira morada. Como o ser humano é constituído a partir de memória e convívio, o espaço e o tempo do cotidiano são elementos essenciais nessa obra. A casa do homem é, antes de tudo, lugar de presença e de construção de histórias. O espanto, essencial para o exame da situação do sujeito, vai encontrar espaços vazios, "lugares-nenhum", hoje multiplicados ao infinito, onde surgem os sujeitos, mas também onde podem eles se perder para sempre. Confirmamos, na análise da história da habitação, que não há uma saúde pública, mas uma saúde coletiva, a ser continuamente inventada a partir de novas versões apresentadas pelos sujeitos na cena da cultura.

Palavras-chave Espaço e Qualidade de Vida; Situação do Sujeito; Subjetividade e Espaço

\footnotetext{
1 Departamento de Saneamento e Saúde Ambiental, Escola Nacional de Saúde Pública, Fundação Oswaldo Cruz Rua Leopoldo Bulhões, $1.480 / 6 \mathrm{o}, 21041-210$ Rio de Janeiro, RJ, Brasil. jorge@ensp.fiocruz.br
} 
à memória de Ênio Tourrasse

\section{Introdução}

Especialmente a monumental cúpula de Santa Maria del Fiore, o grande balão levitante sobre Florença que, pela sua simples presença, redefine toda a distribuição espacial da cidade medieval e a liga aos campos, aos morros e ao território (Lorenzo Mammì, 1984).

A lanterna, ou seja, o elemento que efetua de fato a passagem do céu físico ao empíreo, ou mais precisamente, ao simbólico (...) conjunção entre Florença moderna e Roma Antiga (Giulio Carlo Argan, 1992).

Preferiu sobrepor a ela a sua grande máquina espacial [a cúpula], que visava ao mesmo tempo uma nova concepção de espaço e uma nova tecnologia, como se fosse uma demonstração gigante de uma nova realidade política, cultural, social. Definição urbanística como régio... mais extensa do que área da cidade... a cidade... a domadora de todas (...) os problemas a serem resolvidos ainda são os mesmos: o valor universal do tempo e do espaço como coordenadas da ação humana, em seu acontecimento efêmero e em suas conseqüências infinitas (Lorenzo Mammì in Argan, 1999).

O acontecimento efêmero ao qual se refere Lorenzo Mammì é o convívio entre pessoas que se dedicam, cotidianamente, a construir, juntas, novos espaços de vida. Porque qualquer construção somente é possível dentro de uma significação para o grupo e implica uma escolha. Esse acontecimento se situa, então, dentro de uma ontologia, de uma história do humano e de uma ética. As conseqüências infinitas são as marcas da ação desse gesto de escolha, sobre ambiente, sempre, também, referido ao território da cidade.

O plano civilizatório da pólis se dá, sobretudo, na ação efêmera que o derrama sobre a paisagem e os terrenos, constituindo o feito que chamamos cultura. Para aí convergem as contensões dos sujeitos, ao verem, mais ou menos rapidamente, o valor do seu trabalho permanecer como acontecimento singular e irreversível da ação humana, e mais do espaço social (Mammì apud Argan, 1999). Diríamos que tudo isso se passa porque tal acontecimento dá testemunho da mais profunda intimidade do indivíduo. E falamos, por excelência, das cidades porque a cidade por ser um espaço construído é também um fato histórico. E trata-se, aqui, de uma história vivida por sujeitos em seus corpos. Ela está viva em uma presença geográfica, como afirma Milton Santos, mas essa presença é, no dizer de Merleau Ponty (1984), uma lacuna escancarada e refere-se, segundo a psicanálise, ao prazer, sempre indizível e de impossível registro em um sítio geográfico, nem mesmo em alguma cartografia do saber, pois é por demais tenso, denso e imenso para caber no campo das representações. Os sítios para o homem, como locais de passagem ou de permanência, são pontos de encontro, consigo e com o outro, de onde permanecerão como indícios, rastros de recordações, marcados a partir de uma falta, um sentimento de nostalgia, de um passado no passado. São espaços ligados a épocas, a momentos, à infância, à juventude e a conquistas.

Com a psicanálise, podemos dizer ser essa apresentação única e singular, vivida e situada dos sujeitos, a transformar-se, depois, em representação, aquilo que pode constituir o fato histórico. A história humana somente poderá humana ser, se for a testemunha dessa transformação da carne tencionada pelo $\mathrm{Ou}$ tro - aquele que está mergulhado na indeterminação da cultura e da participação do sujeito em sua encenação - em destino à escrita e à escritura. É nesse fazer - quando o espaço se transforma dialética e poeticamente em corpo, para acolher, no ato sempre inicial do cotidiano, o desamparo constitutivo do humano - que aparece a finitude do sujeito e sua necessidade da linguagem e das representações. A linguagem, a representação, ganha então a digna função de se transformar em horizonte. Com sua estrutura e seus rompimentos, sempre atualizados e retomados, é mais uma alegoria que passa diante de nós.

Assim, a cultura pode aparecer na sua condição inarredável de infinita presença e indeterminação. Nesse sentido, Aparício, Braunstein \& Saal (1980) dizem ser toda arte uma arte funerária, pois o espaço da arte transforma em lugares os espaços onde o nome dos sujeitos são inscritos. Como aqueles que estão nas lápides, esses lugares dão notícia, são sinais da passagem de sujeitos e apontam que a sua história pode ser reconstituída. Ou mais, deve ser re-constituída a partir dos rastros, dos buracos, das faltas, das falhas às quais nos remetem, sinais deixados por nós nas estradas por onde passamos.

$\mathrm{Na}$ re-cord-ação, na ação histórica de colocarmos nosso coração nas coisas - como nos exige, por exemplo, a obra de arte -, podemos 
trazer de volta o ali representado, buscandoo a partir dessa marca inicial, infinitiva. Nesse sentido a obra sempre atual de Giulio Carlo Argan $(1992,1999)$ situa as limitações de um exame do mundo, feito unicamente através do modelo e da ação modelar. A representação, a linguagem, com sua ação de moldagem, fala do passado, do representado, do que já foi presente, do morto. O humano vivo está na dependência dessa representação enquanto aponta a falha, o horizonte, o efêmero.

O advento do cristianismo, com a exigência de encarnação do próprio Deus, limita o campo de ação das profecias e, como somente há salvação onde há riscos, amplia a possibilidade da salvação, elogia os riscos da $e k$-sistência, e a presença da vida passa a ser o privilegiado ato inicial da representação: a cultura renasce das escritas e da escrituras, agora com novas determinações. Esse salto na cultura, trazido pela religião, não nega, pois, o lugar do histórico das lideranças passadas, inaugurado pelo trabalho singular das tradições egípcia e judaica. E é sempre necessária uma visão, uma perspectiva, no sentido de Brunelleschi, nos lembrando infinitamente - para relembrarmos a belíssima expressão de Argan (1992), a nossa finitude. Mas será sempre uma perspectiva, e teremos sempre a responsabilidade de dizermos do lugar e dos instrumentos com os quais construímos a nossa mirada, de onde nasce o nosso nome.

Olhamos os espaços, também, com o prazer do órgão (Freud, 1910) e esse desfrute, esse saboreio, marca da ação vital, é, no dizer do poeta Paul Valéry, aquilo que nos deve levar a não entrar nos espaços sem desejo. A presença ou ausência do desejo transformará o espaço em tesouro ou túmulo, como diz seu escrito no frontispício do Museu do Homem em Paris:

Il dépend de celui qui passe

que je sois tombe ou trésor,

que je parle ou que je me taise,

N'y entre pas sans désir.

As idéias acima expostas podem ser assim resumidas:

- Presença é o fato inicial e imprescindível do cotidiano. Aí se constróem memória e convívio, os rastros de re-cord-ação e os con-textos. - A incorporação nos possibilita assimilar o que a representação esconde. A carne, tencionada pelo outro, possibilita a encarnação de idéias. Os líderes vão à frente, nesse gesto de elevação, pelo simples prazer de beber limpa a pura água da vereda, em alguma mata ainda inexplorada, como nos diz Guimarães Rosa. Com eles nos identificamos e, assim, incorporamos e damos vidas àquelas idéias.

- O corpo reconhece os espaços a partir do desejo. A presença ou ausência do desejo transforma o espaço em túmulo ou em tesouro. $\mathrm{O}$ desejo implica o corpo do sujeito e o Outro, com sua lei. A lei sempre vinda do Outro, da cultura, mais que punitiva ou superegóica, é um norte, um marca ideal, um sinal ideal de um tempo, uma marca histórica.

\section{Memória e convívio}

Precisamos conviver, além de sobreviver. $\mathrm{O}$ convívio caracteriza e inicia a habitação humana, na medida que somente em grupo podemos ver o mundo, traduzindo em movimento, alegoricamente, o infinito imutável do cotidiano. O convívio exige limites, delimitações que se manifestam desde os seus inícios, como contornos das espacialidades, transformando-as em palcos para nossas presenças enquanto vamos construindo signos, sinais, símbolos, metáforas, alegorias. São continentes sem os quais os conteúdos se esvaem. É, para o sujeito, o alumbramento.

Essas significações se superpõem às praças, aos espaços da engenharia e da arquitetura e a tudo que é usado pela linguagem, como o espaço da lei e da legalidade, transformando-os novamente em lugares. Esses lugares - a um só tempo de liberdade e segurança - serão os verdadeiros pontos de encontro e de despedidas, pois são um externo/interno, sempre leal ao sujeito e ao seu grupo, à reunião e à possibilidade de destacamento. Como não existe sujeito sem espaços de convívio, de construção, de memórias, sítios de recordações, não existem grupos sem sujeitos, sempre nãoassujeitados, que se lançam a partir do desconhecido, do inconsciente, o escondido, mesmo do próprio sentimento do si mesmo (Freud, 1914).

O que organiza o espaço, visando a uma viabilidade do convívio, é uma busca contínua da doma da natureza. Domínio, principalmente, daquela natureza que produz, quando em contato com a cultura, inquietação no interior dos corpos dos sujeitos. Somos condenados a essa busca, desde que nos abandonamos e somos abandonados, somos deixados a sós, lançados fora do mundo instintivo, da pachorra 
animal. $\mathrm{Ou}$, mais propriamente, quando ingressamos naquilo que Freud nomeou mundo pulsional. Somos exilados do mundo dito animal, ou o paraíso perdido, embora dele nunca nos consigamos libertar, de forma radical. Nossa raiz é a vida. Vamos fazendo nosso lugar, refazendo o nosso meio, que sempre será, como diz Georges Benko (1994), um mi-lieu, um meio lugar. Pois, para ser um lugar, dependerá do concurso do Outro e de nossa aposta em nossas fundações plantadas na radicalidade da vida, em um território que é vital. De nossa raiz que conservamos, tiramos algo vivo para nosso ponto de vista, nossas perspectivas. Esse ponto de vista, para ser singular, então, é e será sempre um ponto de inflexão em direção a algo sempre novo, em movimento, vivo. Constitui-se, por tudo isso, a partir da capacidade de espanto, de perplexidade. Tem como origem e destino sua contínua formação e o momento sempre inicial de sua constituição.

Parece, pelo andar das coisas, que a fuga, o desprezo por um diálogo, quase impossível, entre os campos do saber e, sobretudo, do saber fazer e do saber transmitir, transformará o conhecimento em algo totalmente ineficaz e dispensável. E isso é importante, pelo próprio fantasma da escassez que sempre ameaça, desde os sujeitos e as potencialidades do espaço-ambiente, a toda a humanidade, transformando em humilhação o desperdício de tempo e de recursos usados com informações inúteis. A competição sistemática tem transformado o saber em mais um objeto de consumo, em detrimento de ser o lugar privilegiado, para a busca de sabedoria, a ser empreendida pelo sujeito, pois é condição central de sua existência.

Essa importância do diálogo se liga, também, aos perigos do acréscimo da violência que faz parte da evolução da cultura. Como assinalou Freud, o recalcamento da animalidade é feito às expensas de algo que pode voltar, a qualquer momento. Esse diálogo é ainda importante porque, para continuarmos na marcha rumo às buscas próprias do humano, devemos percorrer um caminho paradoxal de jamais atingir o esperado, embora tenhamos de nos contentar com o atingido. Como sempre aconteceu, e como bem mostrou Martin Heidegger (1990), ao estudar as vicissitudes da técnica, avançamos fazendo encomendas, produzindo um mundo sempre novo e selando, com isso, um destino, que abandona pelo caminho algumas opções impensadas, ou ainda inaceitáveis. Escolhemos, como podemos, uma direção que nunca será a mesma para todos: há, sempre, os descontentes, a oposição, mais ou menos re-voltada.

Temos insistido no fato de que o homem, o sujeito, não abandona, nunca, a busca de seu lugar, e sobre isto falaremos mais a seguir. Ressaltarei, apenas, que esta busca é sempre um fazer, uma ação singular, sempre transformadora do ambiente, dito natural. E está sempre relacionada a voltas e revoltas, a apresentações, mais ou menos claramente manifestas, mas sempre atuantes, quando realmente se revelam os sujeitos, apesar das boas intenções das representações, que podem ser, elas próprias, as referidas re-voltas ou motivo de revoltas. A intelectualização, muitas vezes maligna, despreza assim, de forma daninha, o novo e as invenções. É quando aparece a idéia do homem normal ou homem "médio", "mediano", que os sujeitos singulares passam, nessa con-sider-ação imaginária, como inomináveis desvios-padrão, em torno dessa média. Essa média é moldada na construção de modelos ditos paradigmáticos. Há um modelo de alegria, de prazer, um paraíso perdido, descrito não somente pela psicanálise, mas também pelas ciências da história e, sobretudo, pela história da arte.

Devemos, no diálogo entre os saberes a que nos referíamos, considerar a correspondência entre o pensamento e a ação, pois cada gesto humano sempre adia outro gesto mais in-pensado. O saber cada vez mais atraente é aquele saber sobre a habitação do mundo e confunde-se, desde a habitação do próprio corpo, com um conhecimento (co-nascimento) sobre o ambiente. Trata-se de um gesto delineado com a transformação do corpo em instrumento de viver. Desde a configuração das mãos, da expressão facial, o saber-sabor, fundado sobre a pisada na cena do mundo, é o instrumento primeiro na modificação do espaço e sua exploração mais ou menos bem-intencionada.

Esse gesto tem deixado aos ambientalistas uma preocupação correspondente à gravidade dos problemas: um círculo vicioso entre a desabitação e a compulsividade voraz em considerar as fontes ambientais como inesgotáveis. Quem trabalha com o ambiente, sobretudo com o ambiente das cidades, deverá aprender a lidar com uma carga de vontades e ações de transformações que se refletem direta e inexoravelmente nos espaços da geografia, da arquitetura e do direito. O preço de re- 
cusar-se a aprender será um profundo mal-estar, angústia e depressão, que violentamente já se mostram sob a forma do estresse. Sabemos que não bastam campanhas educativas para nos levar a uma retomada mais frutífera do sistema motor, conduzida por uma reflexão cada vez mais indispensável. O pensamento exigiria um adiamento das descargas, conforme afirmou Freud, já em 1925. Mas o pensar em ato, a poiesis, em uma produção sempre inicial do mundo humano, conteria as revoltas, conseguindo adiar os sonhos na própria construção de espaços que, ao mesmo tempo, os conservaria, aos sonhos, sempre in statu nascendi.

Assim, o espaço registra, atesta e testemunha percursos e práticas: é o posto de nascimento da ética e da ontologia. Mas essas não são, ainda, as suas mais nobres funções. É preciso compreender, por isso, que o não-lugar traz uma importância complementar ao lugar. E que o vazio, deixado pela vocação mais altamente humana do espaço, como no caso de uma praça - a de São Marcos, em Veneza, é o exemplo clássico do arquiteto francês Robert Auzelle, do ateliê Tony Garnier da École de Beaux Arts da Universidade de Paris - deve dar primazia para este espaço. O não-lugar é como um silêncio. E as novas perspectivas, aquilo que não contém, ou o que não pode ainda con-ter, deve indicar o espaço apropriado para o humano. E assim, re-batido, projetado nas e pelas lideranças, é o futuro, a esperança e a possibilidade de espera o que deve pré-ocupar, concern, no sentido winnicottiano do termo (Winnicott,1982), o verdadeiro lugar: o sítio das espacialidades humanas. É por isso que dizemos: fulano conquistou seu lugar, ou fulano está procurando um lugar.

Olhamos, assim, o sitio a partir de três pontos de vista: como espaço onde se desenvolvem engenharias, arquiteturas e direitos; como território, campo do biológico, da necessidade, da vida e sua vitalidade; e como lugar, que também implica a existência de um não-lugar, ou o lugar-nenhum. Não nos deteremos nas questões do território e do espaço, que com o lugar constituem o que chamo de espaço-ambiente, sítio de sustentação do humano.

O lugar é o local privilegiado para surgimento do sujeito, dispensa os controles, mas aponta para sinais, limites, indícios, limiares ideais, por onde se dá a nomeação. Aí, no lugar-nenhum, que para Georges Benko pode ser todos os espaços de des-aparecimento da iden- tidade e da cidadania e da nomeação dos sujeitos - os aeroportos, os motéis, as auto-routes ou high-ways são exemplos mais gritantes. Por lá, onde o sujeito pode fazer o seu ensaio, sua Probeakion, como observou Freud (1925) em sua reflexão sobre o mecanismo emocional da denegação, ele pisa na cena humana, faz sua apresentação. E desse lugar-nenhum pode se representar o seu mundo, con-ter nessa habitação - que é gesto e construção - seus afetos, seus impulsos. É na tangência das ações nos territórios, espaços e lugares que se dá a situação do sujeito que será um momento de contextuação (Freud, 1974) das alegorias sempre iniciais da significação para os encontros e des-encontros. Podemos afirmar com Kant e Freud que não há memória - e acrescentamos, história - sem espaço e sem tempo. Esse espaço é o que queremos nomear espaço-ambiente. É ponto central de interesse do sujeito, pois lhe aponta limites seus e da ação social suportável, e nele se fermentam os acolhimentos (holdings) (Winnicott, 1982), as habitações.

É incrível que tenhamos de provar algo óbvio para alguns, mesmo depois da des-confiança com que uma nova epistemologia vem enriquecendo a ciência. Como fazê-lo? Sobretudo se é nessa condição inarredável de somente podermos nos encontrar, como História, como perspectiva, esperança, e assim, como presença, naquilo que é perdido? Desse lugar de encontros e desencontros, no falho, no faltoso dos vazios espaciais, o sujeito será, interna e externamente, um originário do $i$-mundo. Tão fragmentado, como o é a sua cidade, também consumida na desmesura de um mundo e um sub-mundo, se encontrará o sujeito perdido querendo sempre descobri-la, modificando-a e modificando-se, isto é, civilizando-se, urbanizando e reurbanizando-se. Um mundo interno nem sempre dizível, nem sempre pronunciável, sem que fique o sujeito mal-dito, no próprio balbucio do seu desejo, na sua própria tentativa de ex-pressão. E as cidades devem contar com os espaços de aventura, que Hartwood (1968) reserva às crianças. Parece que as provas, mesmo as da ciência, deverão contentar-se com ensaios, que, por serem ensaios, serão sempre iniciais.

A fragmentação, o despedaçamento do homem, como dissemos, revela, ao mesmo tempo, uma exposição às seduções do mundo e um exílio de uma situação da qual nunca saiu: a animalidade. $\mathrm{O}$ despedaçamento, sempre incontido, o desamparo pode ser vivido, ao mes- 
mo tempo, no corpo dos sujeitos, o que lhe é mais profundo, e no corpo do espaço multiplicado pelos sub-mundos, nos vazios presentes das cidades, para empregar a forma criada por Ricardo Piglia em A cidade ausente. Essas ausências gritam, na indiferença trágica das administrações e dos teóricos que pensam sujeitos sociais incorpóreos, desvitalizados de suas subjetividades in-domáveis e, ao mesmo tempo, imaginariamente padronizados ou excluídos em desvios, que também imaginariamente eliminariam a possibilidade do inarredável para o sujeito, que é a singularidade, junto com o saudável estado, o qual Joyce McDougall (1978) chama de uma certa anormalidade. É na falha do pensar os locais que surge indomável, não assujeitável, o sujeito.

A presença do sujeito no mundo - suas camuflagens, seu camaleonismo, ou couraças, para empregar o termo caro a William Reich - já nos mostra que o conceito depurado de cidadania não é suficiente para situá-lo. Não há cidadania que sobreviva ao desabrigo; para consegui-la é necessário que o homem seja capaz de produzir para seu próprio sustento. E entendamos tal feito como sustentação no mundo, no con-texto, na situ-ação. Para se sustentar, nem sempre o sujeito é um cidadão. Há a lei e aquilo que não se consegue com a lei como situa Soalheiros (1998).

As idéias acima podem ser assim resumidas:

- Os limites, os contornos, a geografia transforma os espaços em palcos para a cena humana. Aí o sujeito, no grupo, con-tém as revoltas que sempre vêm do corpo, a partir de referências, registros, indícios, rastros.

- O espaço do corpo deve ser domado, e assim se inicia a organização do espaço dito natural.

- É necessária uma capacidade de espanto, uma ad-miração, com todas as origens e destinos que constituem o humano. Com o $i$-mundo como é o mundo interno aos sujeitos, diante do socius.

- No cotidiano se rebatem o presente e a história. É aí que o homem enfrenta o desamparo, e se refaz, re-juntando, no con-texto, sua fragmentação na história e nas geografias.

- A arte tenta apresentar, a partir de restos da atividade humana, o momento da cultura e os nomes que encaminham um entendimento para o ser movimento.

- A incorporação, a encarnação dos ideais é o que fala da vida da cultura: uma língua viva é uma língua de poetas vivos, como diz Liliana Cavani em seu filme Gestos de amor.

- Com o fazer, o céu fica mais próximo da terra, com o fazer na terra, a idéia se transforma em um viver humano.

- Um gesto humano sempre adia outro, mais in-pensado, pensado inconscientemente.

- O espaço-ambiente é o lugar da educação mas é também o lugar da saúde. A saúde é a aceitação do não-lugar como fonte do encaminhamento da vitalidade humana.

- A pré-ocupação (concern) (Winnicott, 1982) é o lugar do nascimento do sujeito.

- É na falha do pensar que surge o indomável, o não assujeitável, o sujeito.

- Há a lei e aquilo que não se consegue com a lei (Soalheiros, 1998).

\section{A realidade do ambiente das cidades. Os sinais do urbano. Urbanismo e seus planos}

Denomina-se, comumente, organização (aménagement) do território tudo que se faz e que modifica a realidade do espaço, em direção ao urbano, à urbanidade, ou seja, à cidade (seja urbis ou pólis). E, portanto, ao que transforma o cotidiano de seu habitante direcionando desejos, através do encaminhamento do movimento dos corpos. Falamos aqui de dispositivos (einrichtungen), os planos, as leis, os desenhos e também de disposições que, mais que legais, correspondem a ações, a cuidados, acolhimentos, manejos, visando à sustentação dos sujeitos.

Afirmamos, em outro lugar, que não se pode fazer intervenções de saúde em pessoas sem endereço. O endereço é um destino, um percurso e um roteiro, indicações sobre movimentos que mesmo o nômade tem. E os membros do coletivo se co-movem com o seu espaço-ambiente. A comoção é um movimento do sujeito a acompanhar o desenvolvimento da cena e as transformações do cenário. Esse sentimento somente é possível na saúde, que aparece sob um sentimento de bem ou mal-estar, fundante da auto-estima, que Freud chamou de sentimento do si mesmo (Selbstgefühl). Esse sentimento é quase sempre nomeado como felicidade, e partem daí os sentidos sentimentos ético e estético. Heberto Lyra afirma que escolhemos nossos espaços com o nosso critério estético, pelo que, para nós, seja o belo. A economia e as finanças pessoais podem for- 
çar os indivíduos a irem para o Rio de Janeiro, Serra Pelada, Volta Redonda, por exemplo, mas eles para lá não iriam, de forma desejante, se esse espaço não lhes agradasse. Um endereço é uma escolha. A prática dessa escolha, exercida através da técnica, é que constitui o viver, a partir de encomendas e destinos por essas encomendas selados (Heidegger, 1990).

É nessa perspectiva que devemos examinar as condições de vida, o território, assim como os espaços: quais os lugares possíveis, sempre de sujeitos? Caso não consigamos o que buscamos, o nosso espaço-ambiente restará, ainda assim, em nós como sonho ou ressentimento, como rancor, ou atuação. O certo é que ficamos sempre mais ou menos despedaçados e, por isso, nos encontramos esmaecidos, esquecidos nos sítios por onde passamos, dependendo da força dos afetos com que os colorimos e da resistência que nos é anteposta. Mas a força com que o esquecido pode retornar é proporcional à intensidade da fragmentação e essa intensidade deve ser sempre sustentada, acolhida e cuidada, no trabalho com as habitações humanas. Por isso os levantamentos visando à saúde devem des-confiar das palavras. O esquecido é indizível, e está no corpo, como sintoma. Esses levantamentos são tentativas de elevação, no sentido de que a teoria re-leva fatos, materiais e afetos a eles ligados. E ao revelar os contornos, limites dos espaços, os suspende (aufhebet), encaminhando possibilidades, impossível tarefa, sem esse trabalho de modelagem, de metaforização.

Vejamos os espaços de que dispomos e pensemos em nossas procuras. Não se trata, nesse diálogo, de falarmos como se não estivéssemos aqui, agora, em um lugar - no Rio de Janeiro, por exemplo. Pois os espaços - eksistem - existem aqui, como coisa que salta de dentro da vida do sujeito - como abstrações. Ou seja, promovem a existência de lugares, localizam os sujeitos como emissores de fala singular, a partir de um real sempre psíquico, que invoca emoções e as con-tém. E esse trabalho de construção do lugar inclui os espaços das virtualidades. Examinemos o dado demográfico. Até a década de 1940, 30\% da população mundial vivia na cidade, $70 \%$ vivia no campo. Atualmente, já se diz que quase $80 \%$ de nossa população vive nas cidades.

O campo deverá se instrumentalizar, se modificar muito, para que as pessoas deixem de se seduzir pelas luzes da cidade. Diz-se que os centros urbanos tendem a se esvaziar, pois os escritórios do futuro serão virtuais e as pessoas se deslocarão para as periferias, com seus computadores conectados a um espaço cuja arquitetura não necessita de dimensões reais. Os sinais do urbano podem estar nos espaços virtuais. Mas é o espaço real que convida, convoca e até intima. E, então, mesmo assim, a animação urbana, embora não conte mais com a efervescência da praça, necessitará ainda de hospitais, de centros de aprendizagem, dos estádios, dos teatros. E, apesar da televisão, não se poderá prescindir do cinema e de sua atmosfera de sonho. O real é o sonho, como em Calderón de la Barca.

A contraposição de um tempo lento, opaco às velocidades ou ao luminoso, magnífico instrumento de análise inventado por Milton Santos (1993), não poderá deixar de considerar que um não existe sem o outro, fascinando sempre quem está no lado oposto. O campo hoje é a cidade de antigamente, como a medicina popular é a medicina científica antiga (Boltanski, 1979) e se renova sempre guardando suas técnicas e espaços antigos, como lugares do esquecido. É assim que a estrada de pedra, o moinho de vento, a muralha e a coluna grega são, segundo Le Corbusier, ruínas comoventes - diríamos co-moventes. E é assim, também, que não se sabe mais se peão de boiadeiro é uma invenção rural ou urbana ou se o adulto em sua habitação, circulação e trabalho, e mesmo no desfrute do mundo (dodo, boulot, métro, ou seja, naná, trabalho e metrô, como se dizia em Paris, em 1967-1968), vive uma vida muito diferente da vida infantil, na medida que adia, no sintoma ou no sonho, o ideal do crescimento. Essa organização para a cidade está em um plano em que a repetição transforma os movimentos dos corpos em pura mecânica de máquinas, em que a energia de seus sonhos vem de uma ação externa.

Estas cogitações são de central importância para se pensar a cidade. É verdade que a organização urbana precisa considerar os efeitos da demografia, como aqueles relativos às diferenças de idade e de sexo, à composição da população, à diferença de classes e à sua distribuição no espaço e, ainda, aqueles ligados às formas de vida aí encontradas, sobretudo aquelas relacionadas ao incremento da violência. A demografia nos ajuda a fotografar. A população da cidade do Rio de Janeiro passou, no período de 1991 a 1996 , de 5.480 .768 para 5.551.438 habitantes, crescendo um percen- 
tual de 1,28 . As favelas cresceram, no mesmo período, $69,43 \%$.

A taxa de fecundidade brasileira, o que mais influencia o crescimento populacional, segundo o Banco Mundial, caiu de 6,3 filhos nascidos-vivos por mulher, em 1960 e chegou a 2,8 no ano de 1993. A taxa de crescimento passou de $3 \%$ ao ano, em 1960 , para $1,6 \%$ na década de 1990. Esses dados interessam à programação da atenção à saúde, educação, recreação, esporte e lazer e de todas as preocupações do urbanismo. Mas nenhum dado, por mais elaborado, nos poderá ajudar a prever, a produzir, um plano invulnerável à ação dos sujeitos. Um plano, assim, aliás, não teria utilidade. A depredação de equipamentos urbanos, com o que o pessoal ligado ao escoamento de dejetos, ao abastecimento de água e a centros comunitários têm de lidar desde sempre, é testemunho disso.

Há outro trabalho a ser feito se pensamos em manutenção. O ato de criação e de inauguração é a preocupação maior do político. Nosso tempo, o tempo do que pensa a questão, deve ser mais lento: é com o tempo da permanência - habitação como demeure - o nosso maior cuidado. Para isso a invenção deve vigorar. Não podemos ficar indiferentes a fatos como a reconstrução de barracos em áreas de risco, onde já houve desabamentos e onde já se promoveu uma evacuação anterior de moradores, com a intervenção do poder público. Esses moradores não ficarão indiferentes a nós, quando lhes levarmos saúde, educação ou qualquer outra coisa. É na insistência, na morada, que se constituem as crenças. Há uma insistência (beharrarung) e um gesto no esperar (haren) presente em todo totem, como afirma Freud, no seu livro Tótem e tabu. Se, de um lado, há uma animação do inanimado, no totem, há, por outro lado, uma de-existência, também fruto do pensamento mágico infantil, no gesto de habitarmos aquilo a que chamamos de lugares-nenhum (Benko, 1994), tema que abordaremos mais adiante. Quando saltamos de posições que nos foram dadas para a conquista de nosso lugar, nosso nome, fazemos uma de-existência. René Major em uma de suas conferências nos lembra que Freud o fez, quando renunciou à biologia e as questões de raça, abraçando os temas da cultura para situar as bases da constituição do sujeito humano.

Embora no Rio de Janeiro, a população se mantenha relativamente estável, os quatro principais complexos de favela cresceram cin- qüenta vezes mais rapidamente do que o município todo. O complexo da Maré, de 1991 a 1996 , cresceu $68 \%$, ao passo que a cidade cresceu $1,25 \%$, no mesmo período. Esse crescimento tem conseqüências. O índice de homicídios e roubos é sete vezes maior na Maré e, em 1991, a taxa estimada de homicídios para Bonsucesso foi de 241,1 homicídios por cem mil habitantes, enquanto na Lagoa, Jardim Botânico, Humaitá e Flamengo chega a zero. Lá, os domicílios familiares são divididos e reduplicados - em termos de ocupação e fragmentação e quase nunca reduplicados em termos de área a cada separação de casal e casamento de filhos e a cada chegada de família de outras partes do país. Ali os serviços urbanos são precaríssimos.

Podemos imaginar as condições de vida na favela, pela observação das áreas ditas urbanizadas. O canal do Mangue, na altura da praça da Bandeira, escoa, nos dias normais, uma piscina olímpica a cada dez segundos, e, em caso de enchentes, necessitaria escoar quatorze. $\mathrm{Na}$ favela essa realidade é catastrófica devido à erosão, com os escoamentos mal encaminhados, sobretudo nas favelas de encosta de morros. São 2,5 milhões de favelados no Estado do Rio.

São apressadas as análises ao relacionarem delinqüência e pobreza, mas não o são aquelas que associam delinqüência a empobrecimento. A forte melancolia e depressão diante das perdas e da ostentação, sempre impostas por uma sociedade de consumo, aumentam, também, com o desligamento de responsabilidades, com a construção e a manutenção e com os cuidados com a sustentação, que colaboram na doma do mundo pulsional. Esse malestar liga-se, ainda, à ausência de recompensas pelo adiamento de satisfação imediata, delineadas em horizontes alcançáveis, e sempre obtidas, com a alegria da prática. Esse adiamento somente é possível com a aceitação das tensões vindas das diferença de posições, com a valorização do questionamento a um sistema institucional (...) e à análise das estruturas sociais que o sustenta, levando-nos à crítica da neutralidade científica (Basaglia, 1985).

A construção de espaços que são feitos a partir de lugares, de possibilidades de busca, de situação para os sujeitos é conseguida, às vezes, a partir de comportamentos não muito recomendáveis. Aquela alegria é sempre possível onde corre a verdadeira solidariedade, que não pode desconhecer a solidão inerente à precariedade humana, e que constitui o central 
da busca dos sujeitos, pois aí reside o encontro e o encontrar-se. É onde o convívio relembra o que a memória nos re-conduz a uma crença vinda de nossos fundamentos, nossas fundações, que sempre podemos, com alegria, re-começar. Falamos desse lugar de invenções, de nascimentos, quando fomos acompanhados, ajudados mesmo, na fragilidade, em nossa impotência inicial, a vencer desamparos a serem, desde então, para sempre revisitados.

Essas cogitações nos levam a crer que um programa de financiamento de terrenos - servidos com abastecimento de água e sistema de esgotamento e de drenagem de águas pluviais, rede elétrica - e de materiais de construção seria mais digno e habitável, do que os verdadeiros acampamentos, com quilômetros de repetição e sistemas sanitários mínimos das chamadas habitações planejadas. Todo habitante paga impostos desde o pão matinal até a condução, vestuário, trabalho, entre outros, merecendo - e não esquece esse merecimento (Freud, 1974) - uma solução técnica conveniente e digna, de forma solidária e igualitária. Dizemos igualitária, conscientes da questão da singularidade, mas também do direito de inclusão nos direitos quando somos todos incluídos nos deveres. Como poder-se-ia fazer um trabalho de mudança em que, desde a concepção, a invenção e a instrumentação técnica, não nos envolvêssemos com a exclusão até mesmo de colegas que pensam de outra forma? O sonho ambientalista fala de uma autosustentação ambiental. Pode um homem não acolhido, não sustentado por seu espaço-ambiente, sustentá-lo?

As idéias principais do presente capítulo são as seguintes:

- As concepções técnicas, os dispositivos, devem implicar disposições, pois a uma organização interna corresponde uma organização externa. A saúde já está nas espacialidades, e o prazer do técnico deve ser o resultado de uma identificação com o usuário. $\mathrm{O}$ acolhimento é um rebatimento, uma projeção, no espaço de um encaminhamento da utilização da energia da natureza na arm-ação (Heidegger, 1990) de cada técnica.

- A auto-estima ou amor próprio é o sentimento do si mesmo (selbstgefühl), vindo também com a confirmação pelo ambiente de projetos pessoais (Freud, 1974). E se dá com um sentimento de bem-estar, um conforto do acolhimento no mundo. A esse sentimento de prazer, comumente se dá o nome de felicidade.
- O espaço pode estar em nós como sonho ou como ressentimento, rancor, lugar da ação (acting) a acionar o sistema motor, quando o pensamento poderia adiá-lo, visando à reflexão sobre um melhor caminho.

- A cidade e sua animação possibilitam uma atenção específica, onde re-encontramos uma necessidade de satisfação. $\mathrm{Na}$ realidade, não encontramos nada, apenas re-encontramos (Freud, 1905) mas para re-encontrar aquilo que sempre interminavelmente procuramos, precisamos encontrar e nos encontrar. (Sami-Ali, 1974).

- A criação e a invenção são pontos de partida no cuidado com o espaço. É preciso oferecer condições de criar: o material, o financiamento, o terreno, os equipamentos sociais urbanos.

- A exclusão promovida pelas teorias e pelas técnicas acirram a violência?

- Pode um sujeito, sem a experiência de acolhimento, acolher?

\section{A evolução do trato com a organização (aménagement) do território: a teoria e as instituições}

Esse predador sistemático [o homem] busca, dentro dos formigueiros gigantes que edificou, interesses de sobrevivência e de satisfação nem mais nem menos estimáveis que os das toupeiras, ou dos cicindelídeos (Alain Badiou, 1997).

Diante dessa realidade, devemos pensar como vemos o meio ambiente. A pesquisa "O que pensa o brasileiro sobre o meio ambiente", realizada pelo Ministério do Meio Ambiente (MMA), em 1992 e repetida em 1996, mostra dados e modificações interessantes: dois terços dos brasileiros acham que o meio ambiente é sagrado e não deve sofrer interferência. Verifica-se uma concepção naturalista do meio ambiente. Entre os de formação universitária, foram 38\%. Poucos (29\%) pensam que a favela e a cidade fazem parte do meio ambiente; assim pensam 39\% dos que têm mais alto nível de escolaridade.

A animação do mundo, iniciada com o pensamento mágico infantil, nunca abandona o gesto humano. A própria organização do espaço é vivida como um descaminho. É o avesso do corpo. O corpo humano necessita de uma organização do espaço de sobrevivência e de convívio, onde deve sustentar-se e conter-se. Suas atitudes mais viscerais nos levam a crer, 
entretanto, que dispensaria de bom grado tudo, por um momento de excesso. Não seria por outra razão que, magicamente, considera, às vezes, a terra e o Outro, como inesgotáveis.

Nesse sentido o verso de Chico Buarque 'te adorando pelo avesso' nos mostra que a própria língua é revirada para dar conta da realidade emocional. Somente se pode adorar, quando o fazemos, pelo avesso do humano, pois o homem não pode existir, como sujeito, adorando o outro. Seria o fim dos corpos, das presenças e dos encontros. Nessa adoração elegemos ideais que pretensamente nos irão oferecer o que desperdiçamos e que não pode retornar, senão na magia, no mundo do fantasmático ou fantasioso. A natureza sagrada, adorada, seria inesgotável para um conforto já reencontrado, em um paraíso nunca abandonado, sem necessidade de encontros, de procuras.

Continuemos com a pesquisa do MMA. Da população da amostra, 43\% acham que somente o povo e o governo brasileiro devem lidar com o meio ambiente, e 39\% pensam que devemos agir em cooperação com outros países. O desmatamento da Amazônia interessa ao mundo todo, segundo 58\% dos brasileiros, entre os quais $69 \%$ da população do Norte. Um terço da população acha que a Amazônia é de inteira responsabilidade dos brasileiros. Quanto às árvores, $66 \%$ concordam que se pode usar, cortar, que crescem de novo; no Norte do país, $49 \%$ da população discorda e $42 \%$ concordam. Quando ao uso da água, 35\% da população do Brasil pensa que, se continuar como está, dentro de pouco tempo não se terá água para beber. No Norte do país, $42 \%$ da população está de acordo e 45\% discordam desta afirmativa.

A técnica da administração pública é iniciada com o Estado-Nação. Essa opção, como qualquer outra da cultura, é sempre assumida de forma ambígua. O mais ferrenho defensor do público terá seus momentos in-confessáveis - somente confessáveis para si mesmo, pois, pelo que tem de interditado, resta inconsciente - de adesão à forma privada de organização. Essa reflexão, profundamente enraizada na psicanálise dos movimentos do ego, nem sempre agrada a alguns teóricos do social. Ao mesmo tempo em que se vê o espaço comum como terra de ninguém - um lugar-nenhum -, pode-se considerá-lo como propriedade privada. E o que é privado é assumido pelo sujeito, nas profundezas de sua subjetividade, co- mo um espaço do sonho e do mito. Há uma apreensão, uma pulsão de domínio, nos primórdios da vida emocional - o bebê leva tudo à boca no seu início de saber-sabor, de degustação do mundo. O próprio direito reconhece como uma propriedade privada, somente quando se tem o direito de destruí-la. Com relação ao meio ambiente e às condições de emprego, a pesquisa revela: dois terços da população não aceita poluição para a geração de emprego, 27\% concordam em priorizar o econômico e $47 \%$ da população confere primazia ao meio ambiente.

Three Milles Island, Minamata, Seveso e outras catástrofes ambientais não demovem as pessoas de suas convicções. É mais provável que a notícia do pânico produza denegações e leve ao apagamento, no psiquismo, de fatos desagradáveis. O emprego e as possibilidades de gastos ligados a uma outra lógica que não a da saúde pública, como aqueles com os eletrodomésticos, a televisão à frente, são colocados em primeiro plano, na vida das pessoas, competindo mesmo com o abastecimento de água corrente. Por isso defendo a nomeação de saúde coletiva para as atividades públicas de saúde. Assim teremos as vicissitudes ligadas aos imaginários, e portanto do subjetivo, realmente consideradas. A noção de perigo e de risco são outras para o sujeito e não são passíveis de descrições por uma fenomenologia mesmo que muito bem-intencionada.

Com relação à questão sobre meio ambiente, a pesquisa revela que $50 \%$ da população se acha bem-informada; um terço se acha malinformado. Quanto maior a escolaridade, maior o sentimento de ser informado. Houve pouca mudança desde 1992. Quanto às ações de proteção, em 1992, 51\% pensavam que deveriam ser de âmbito federal e, em 1996, 43\%; cresceu a quota de responsabilidade atribuída às prefeituras. Quando se fala sobre instituições, o Ibama é o mais citado. Oitenta por cento da população aprova as organizações que trabalham com a proteção do meio ambiente. A fiscalização e as leis rigorosas para as empresas são aprovadas por $55 \%$ e $47 \%$ da população, respectivamente. E a prisão para queima de matas é aprovada por $46 \%$ da população; para os pichadores, é aprovada por $34 \%$. Nas capitais, $45 \%$ da população acha que os pichadores devam ser presos, contra $8 \%$ em 1992. Multas devem ser aplicadas para quem constrói em locais protegidos por leis ambientais, para quem fuma em locais proibidos, usa 
esgotos clandestinos ou caça e pesca em áreas onde essas atividades são proibidas.

As informações, como conhecimentos adquiridos, e arquivos mnêmicos, têm pouca valia diante dos gestos. $\mathrm{Na}$ alma das pessoas vigora uma formação (bildung) interna, que implica, sempre, possibilidade de re-invenção de lugares, liberdade para misturar conceitos, recriar técnicas, arm-ações (ge-stell) (Heidegger, 1990). E isso não deve ser esquecido por quem lida com o acolhimento ambiental. Não se trata de acumular informações, o que certamente está ligado, hoje em dia, à venda de cursos e conferências. Essa idéia era a defendida pelo professor Paulo Freire quando militava contra uma concepção bancária de educação.

Pode-se lutar, entretanto, por um movimento de responsabilidades em direção às esferas locais e por uma aprovação maciça, aí mesmo, de todo tipo de trabalho em direção ao meio e à sua habitação. Mas deve-se desconfiar de militâncias com claras características fóbicas, de exclusão portanto, com relação ao fumo, à carne vermelha, ao grafitismo e outros movimentos que apresentam, às vezes, a punição impiedosa como solução. O castigo, já nos mostrou Bruno Bethelheim, não educa.

Com relação ao trabalho voluntário em prol do ambiente, podemos acompanhar movimentos importantes: $66 \%$ dos jovens são interessados. Desses, $60 \%$ têm instrução mínima de nível técnico (na região Norte, $64 \%$; no Nordeste, 63\%; nas cidades de até $20 \mathrm{mil}$ habitantes, 62\%). A disponibilidade para contribuições financeiras revela um engajamento de $39 \%$ dos jovens e o mesmo percentual dos moradores do Norte e Nordeste estão disponíveis. A disponibilidade de se tornar membro de entidades se dá em menor proporção do que para se envolver em trabalho voluntário. A proporção da população mais instruída em mutirões de reflorestamento é de $19 \%$ e a contribuição financeira possível para essa atividade é de 3\% da população. A obrigatoriedade da educação ambiental (uso e preservação) é defendida por $93 \%$ da população; o Norte e o Nordeste têm, respectivamente, $75 \%$ e $69 \%$ de adeptos.

Esses dados falam por si, mostrando os limites e as profundidades da opção dos mais instruídos, que sempre optam por métodos educativos fundados na punição e na obrigatoriedade. Não pretendemos aqui, desenvolver uma visão vol-d'oiseau do que tem sido a teorização em torno do Urbanismo e do Planejamento Urbano, ao longo da história. Ressaltaríamos somente que vivemos, na organização do espaço, de retomadas de algo que foi perdido e que parece teimar em querer voltar, apesar, sobretudo, das intensas e criativas manifestações dos teóricos. Françoise Choay (1992), em sua tese de doutoramento Urbanismo: utopias e realidades, dividiu o caminho do saber sobre a ordenação do espaço, bem ao gosto estruturalista, em dois movimentos: um culturalista e outro progressista, além de um urbanismo naturalista. Houve, para a autora, um pré-urbanismo culturalista como em Augustus Pugin, John Ruskin e William Moris; e um pré-urbanismo progressista como em Owen, Charles Fourrier, Victor Considérant, Etiène Cabet, Pierre Proudhon e Júlio Verne.

Para Choay, alguns teóricos não tinham um modelo de análise e intervenção no espaço, como é o caso de Engels, em seu estudo sobre o problema do alojamento, e como o de pensadores que viram as aglomerações urbanas como lugares de uma utopia da técnica e da vocação para uma vida tecno-cultural, mais marcada pelas diferenças dos sujeitos, relativas às outras espécies, como é o caso de Eugène Hènard, de Iannis Xenakis e do Relatório Buchanan. Aborda ainda a autora pensadores como Patrick Geddes, Marcel Poète, Jane Jacobs, Leonardo Duhl, Kewin Lynch e Lewis Munford, os quais pensam a cidade, desde uma organicidade que parte do humanismo. Choay trabalha as idéias de Tony Garnier, BenoitLevy, Walter Gropius, Le Corbusier e Strumilin, como as de um urbanismo progressista e as concepções de Camilo Site, Ebenezer Haward e Raymond Unwin, como as de um urbanismo culturalista. Situa também uma filosofia da cidade a partir das idéias de Victor Hugo, Georg Simmel, Oswald Spengler e Martin Heidegger.

O que nos interessa aqui é ressaltar uma perspectiva que ora privilegia o pensamento e a importância do pensar, pois o desejo é o que governa, doma os impulsos, e ora o corpo e o sensível, esse, às vezes, valorizado por demais em sua biologia pelos ecologistas como um corpo animal. Não restam dúvidas de que a pólis e a urbis se desenvolvem a partir de um ordenamento social dos desejos, de leis. Mas elas também estruturam um espaço, cujo acesso à percepção e à legibilidade facilita ou dificulta a vida das pessoas, tornando-a mais 
fácil ou mais difícil de ser vivida. É o campo do traço ou o risco de uma engenharia e arquitetura estranhas (unheimliche), acolhendo comportamentos estranhos, uma vez que devemos admitir existir aqui uma razão da desordem. O trabalho de Gordon Cullen (1968) é uma preciosidade em torno dessa questão do traço no urbano. Ali o traço tende a trazer o ambiente para uma ordem mais próxima à vida intima, interna ao sujeito, o que seria para o externo uma desorganização. Mas nem toda a desorganização interna pode ser desenha$\mathrm{da}$, porque apenas pode ser prevista internamente, a cada instante da vida do sujeito.

Tendemos a crer que as instituições não cooperam muito. Por isso afirmamos que um acesso ao terreno e ao crédito talvez fossem as únicas providências a serem tomadas pelo poder público quanto à habitação. A situação do sujeito, sempre condicionada ao corpo, a seu conforto e à técnica, portanto, está amarrada às espacialidades. A inquietude do homem, suas navegações infindáveis não o eximirão jamais de viver sem água e sem se preocupar com o espaço para onde a dispensará depois de usada. Não há como pensar em uma cidade onde falte água por quinze dias seguidos.

A perambulação humana foi acompanhada pela teoria sobre seus deslocamentos e fixações. Criou-se uma teoria que acompanhou os Ciclos, as Redes, os Pólos e a sua complementaridade. Milton Santos (1993) chegou a criar uma teoria unitária em que juntava o movimento à inércia: os fixos e os fluxos. Acrescentaríamos que fluxo, para o sujeito, não é o mesmo que rotina ou ritualística. É o lugar da pulsão, daquilo que não tem governo e uma teoria unitária não alcançaria esse movimento em todos os sujeitos. Freud inventou a teoria pulsional, ao perceber que as representações não dariam conta da inquietude do sujeito. Seria necessário, como dissemos, um contínuo acolhimento da apresentação dos sujeitos que se deslocam nos palcos do seu espaço-ambiente, para se falar de algo vivo, da teoria para um traçado, para uma geografia com lugares para o sujeito e portanto para o inusitado, para o risco. Os arquitetos ou engenheiros medievais eram conhecidos como mestres do risco, cabendo, nessa metáfora, o perigo na execução de um projeto para as volutas de uma catedral, que eram traçadas na medida que eram construídas, as tensões sendo examinadas na medida que eram ajuntadas as pedras.
Para eles as pedras eram tão importantes quanto o traçado do arco, como mostrou Ítalo Calvino em seu livro Cidades invisíveis.

Um movimento a situar a periferia como sítio de consumo de pensamentos e práticas oriundos dos centros de produção da cultura - que pode ir até um mundo que não sabe de si mesmo - deve convocar algum exame. A verdade, quando vinda de um só centro, é como a luz vinda da boca da caverna de Platão. Como nos diz Badiou (1997), o problema está em querermos, quando chegados do centro, convencer a quem está nas sombras, de que vimos a verdade.

Por isso, as cidades aparecem, na literatura e na arte, como divididas, partidas, invisíveis, ausentes, minerais (de quartzo), como utopias e como sede de democracias ou ditaduras, ou formas imaginárias para situar vidas pré-tensamente governáveis. O possível, na compreensão do fato urbano hoje, está, pois, mais próximo da arte. Com a modernidade, a arte se separa definitivamente da técnica. Se, até Platão, a arte (poiesis) e a técnica (tekné) andaram juntas (Heidegger, 1990), algum esforço devemos fazer, acompanhando Argan (1999), para ver a dialética clássico-anticlássico, contida em toda produção humana e não somente no trabalho da arte. Então, a ciência, não estaria, tão obsessivamente, presa a modelos. Na época clássica eles deveriam ser procurados e repetidos à exaustão. Estavam já na natureza, eram graça divina a ser encontrada. E mesmos os grandes mestres faziam esforço sobre humano para colocar uma idéia nova, dita anticlássica.

Resumindo as idéias deste capítulo, poderíamos dizer que o ambientalismo não comporta teorias messiânicas.

- Nas práticas ambientais, a sua teoria sempre deve con-ter a perspectiva do outro. É nesse sentido que para vários autores nada é mais eficaz do que uma boa teoria, que seria refeita continuamente, reconhecendo-se no lugar da representação. As teorias oscilam entre um espaço organizado, segundo leis que seriam as da natureza e aquelas que se formam seguindo um conforto, que direta e incessantemente, os corpos dos sujeitos demandam.

- O fluxo, nas cidades, é regido pelo desejo que, às vezes, é de permanência. Nesse sentido, habitação é demeure, morada.

- A evolução da organização do espaço caminha para uma aproximação poética dos elementos em seu con-texto. 
Aquilo que fica de fora: o espaço, a desterritorialização e o território humanizado; o lugar-nenhum e o lugar do sujeito

...choc-Erlebnis de Benjamin... a metrópole não é mais cidade... o objeto é substituído pela imagem, pela escrita luminosa. A arte, que produz objetos-que-têm-valor, é substituída por uma experiência estética, cuja finalidade não pode ser outra que a criação de imagens-choque, de sinais, de notícias elementos urbanísticos. (...) a profunda função estética do mundo não citadina, em que se desconhece a superação tecnológica e talvez também, o ocultamento que a techné faz do erlebnis (Bruno Contardi, in GC Argan, 1992).

A vivência-choque, citada por Benjamin, é o espanto, a perplexidade, pois a vivência (erlebnis), implicando aventura, é a apresentação da vida, no simples gesto do viver, com a busca de lugares de encontros. Como a vida humana implica convívio, toda apresentação dos sujeitos se dispõe em direção à representação, a essa outra praça, esse outro ponto de encontro que é a língua, o simbólico e a história. Se teorizamos sobre o viver humano devemos falar sobre outros humanos e devemos, pois, ir ao seu encontro. O início do humano está no sonho e o ato de encontrá-lo - que Freud chamou de anstoss, e que tem, sem dúvida, um choque inicial - é surpreender-se com o aparecimento da imagem, no alumbramento, para empregar a linda expressão de Manuel Bandeira em sua Evocação ao Recife (1986). Mas essa imagem deve ser construída, formada (bildet), no ritmo do sujeito, que está sempre buscando uma história, uma narrativa, um esclarecimento para o gesto do seu viver.

Esse choque, entretanto, não pode mais ser negado e, por isso, devemos retomar a teoria da angústia para, em um movimento inverso ao da psicanálise, assim podermos nos enriquecer com o saber da filosofia e dar um novo lugar para a perplexidade e o espanto. Somente dessa maneira, poderemos nos situar diante do que se tem chamado de objeto, ou mesmo a coisa, (das Ding ou la chose) (Heidegger, 1958), ou qualquer ponto que despende em nossas perspécticas para, mais uma vez, empregar o saber infinitivo de Brunelleschi (Argan, 1992,1999) e seu dispositivo de compreensão do espaço que era, ao mesmo tempo, de entendimento da História. Somente nes- sa perspectiva, ou perspéctica, poderemos nos aproximar do que chamamos de lugar-nenhum.

O lugar-nenhum é uma aproximação cuidadosa para espaços da tardia modernidade, trazida por Benko (1994), que devemos valorizar, apesar e justamente por causa do choque do mal-estar e do estranhamento que esse lugar pode trazer. Lembremos que o malestar está associado à angústia, ao medo, ao susto, ao choque. O que é traumático nos leva à repetição, na procura de seu entendimento: na verdade é como se nos situássemos, diante de um acidente, sempre e repetidas vezes, querendo, depois do ocorrido, magicamente, paradoxalmente, estar em momentos anteriores, e nos munirmos, assim, de instrumentos para enfrentá-lo. A entrada na vida, que se dá a todo instante, tem, no lugar-nenhum, oportunidades de re-apresentação, e portanto de simbolização e de compreensão, de pequenos traumas, agora controláveis pelo sujeito.

A possibilidade de um trabalho significativo com a organização do espaço urbano e regional parece ter se transformado em uma utopia, em algo impossível, para além das teorias e dos bons desenhos. $\mathrm{O}$ atendimento às necessidades das aglomerações em termos de emprego, saneamento, transporte, educação, lazer, dos espaços de moradia, resultaria em dispêndios vultosos. Produzir um retorno ao campo, parece um sonho ainda mais estapafúrdio. Pensar biosferas como as do Arizona, lugares onde estaríamos protegidos de tudo, parece delírio desnecessário, sobretudo para um país pobre. O entendimento, reconhecidamente em crise, em torno de teorias e de práticas, de agrupamento de técnicas, parece improvável, sem uma transdisciplina, um gesto de comoção, que dependerá do reconhecimento do que Brunelleschi e, depois, Argan chamaram de perspéctica.

As proposições mais interessantes tem sido conseguidas a partir de uma ética do continuar, de uma possibilidade do impossível (Badiou, 1997) cuja manifestação central seria a da consideração da inclusão local de sujeitos, em uma época de exclusões. O próprio Movimento dos Trabalhadores Sem Terra, único movimento social do Brasil no momento, exclui os jecas-tatus e os lúmpen.

Vivemos, entretanto, em um mundo onde as pessoas estão cada vez mais desapercebidas. As liberdades e as espacialidades impessoali- 
zadas fazem os sujeitos ao mesmo tempo empreenderem uma busca desenfreada por identificações e referências e, por outro lado, quererem desfrutar esse espaço do vazio, onde terão um tempo infinito para se re-encontrarem. É o caso dos sem-nome e sem-número, submetidos a uma miséria radical, pois sem possibilidade de escolhê-la (Carneiro Leão, 1992), portadores até mesmo de cartões magnéticos, ou em uma Geografia de Lugar Nenhum (Benko, 1994), como os espaços de alta rotatividade dos motéis, aeroportos e auto-estradas, por exemplo.

Voltamos a insistir, com Freud, que não encontramos nada, apenas re-encontramos. Não desistimos de nossos verdadeiros mestres, aqueles que nos trazem o saber como sabor, como dizia Roland Barthes. Nossas identificações, nossos espaços de re-cord-ações, que são rastros, indícios, pistas em nossa memória (erinnerunspuren) se vão transformando em um espaço encorpado (embodied), ou de incorporação (verkörperung), personificação do corpo próprio. Somos revitalizados, na medida que o sonhamos, em que vamos construindo nosso sonho, ao vivê-lo mesmo, pois como já nos mostrou Calderón de La Barca, la vida es sueño. Espaços que vão, assim, se tornando nossas habitações, nossas construções, nosso pensamento, os três momentos concomitantes da morada humana, no pensar heideggeriano (Heidegger, 1958). A habitação ou o túmulo, a teoria ou a inscrição funerária, ganham vida quando trazem a vida. A nossa ou a dos que nos sucederem. É nesse sentido que Homero afirmava que os demônios do submundo da Odisséia ganham vida quando provam sangue. E é no mesmo sentido que Freud se refere às lideranças. E a análise institucional representa as maquinações do poder.

Uma des-habitação e uma desterritorialização têm levado os sujeitos a um descuido com o ambiente. Pois os sentimentos ligados a esses estados não permitem uma avaliação correta das possibilidades de seu corpo e, portanto, do que a ele não pode faltar e do que, para ele, é falha constituinte. É inútil, pois, uma militância ambiental para pessoas, descorporificadas e desespacializadas. Falamos de espaços próprios para o humano, que devem prever o necessário para o biológico, mas também para a criatividade, para a inventividade sem a qual o homem humano não existe. $\mathrm{O}$ espaço deve incluir, assim, uma óbvia possibilidade de vida e de sobrevivência. Mas deve per- mitir para além do controle, preocupação principal dos desenhos, um lugar sempre de des-adequação, lugar do sujeito e do novo. Como? Tentando-se, como é de costume da vida.

O trabalho com o espaço deverá, agora, considerar um novo momento dos sujeitos, que já se procuram nas virtualidades, mas que não podem mais adiar uma re-volta contínua, presente na busca de espaços esquecidos, de corpos des-habitados. Essas revoltas, essas buscas, às vezes, compulsivas na motricidade, desenterram uma série de técnicas alternativas para o corpo. Uma institucionalização de práticas a ele ligadas - das cirurgias plásticas e consultas para nutrição adequada e dietas, até as academias, as tatuagens e o pearcing - o tem mortificado cada vez mais.

É assim que vamos re-solvendo, dissolvendo, infinitamente - diríamos com Freud e Argan -, sempre velhas tensões e velhas transferências, agora, mais ainda de forma imperativa, pois caímos no vácuo dos espaços das redes telemáticas. Esses espaços são, agora, aqueles onde a intimidade é trazida para o mercado. Diante disso, o corpo humano não pode mais adiar os movimentos, que sendo humanos devem ser criativos, por mais interditados que sejam, em direção aos lugares. Lugares nunca a priori desenhados, onde o homem deve, paradoxalmente, perdido, se re-encontrar em uma indagação, fundada em uma indignação que o legitima. Indagação sobre o destino dos sítios e da sua situação de sujeito, a eles diretamente ligada. Nesse movimento serão re-encontrados a memória e os convívios, em encontros e des-encontros.

Parece que o sujeito estará, cada vez mais, exposto à fadiga e ao mal-estar, no seu destino interminável de procura de um lugar, diante de um exército de supérfluos em que foi transformado juntamente com seus semelhantes. Mas parece, também, que aqueles envolvidos com o poder, o controle e a administração estarão mais propensos à desilusão. Os espaços reservados pela modernidade tardia, se deixam os sujeitos mais perdidos, também os deixam mais difíceis de serem encontrados, sobretudo para uma lealdade tão desejada pelos governos.

Podemos dizer que qualquer pensamento atual sobre a qualidade do ambiente deve partir dessa des-qualifição própria dos lugares. Dessa multiplicidade de vias de ek-sistência, trazida agora, pela civilização, com uma pos- 
sibilidade de descorporificação das presenças vindas com a proliferação dos lugares-nenhum. Diríamos, uma des-corporificação - presente nas redes de acesso público, a contarem agora com a telemática, e nos novos enredos da arte possibilitando, aos sujeitos, em todo o espaço da cidade uma vida que é, ao mesmo tempo, memória e convívio, apresentação e representação.

Esse fato nos revela um homem com mais possibilidade de liberdade e, talvez, por isso mesmo, tão caçado e cassado pelo poder.

As idéias principais do presente capítulo são as seguintes:

- Há um ocultamento do mais profundo da vivência, para que o sujeito se preserve como tal. Esse ocultamento está ligado ao choque com o ambiente e à capacidade de espanto que é vivida no próprio corpo e se dá de forma efêmera.

- A capacidade de espanto é condição central para se entender o espaço necessário para os sujeitos humanos.

- A psicanálise sozinha não pode delinear os caminhos do sujeito no espaço-ambiente, mas é por onde poderemos ter uma idéia inicial dos pontos de partida.

- O transdisciplinar, antes de ser um espaço disciplinar, é um lugar de abandono de saberes a priori constituídos. O desamparo inicial, constitutivo do humano, revivido nesse abandono é essencial para a compreensão do que seja o espaço-ambiente, necessário para uma situação do sujeito humano.

- O verdadeiro mestre é o que reconhece a existência de outros ideais.

- O mesmo espaço, se encorpa, nos acolhe e é por nós incorporado, na medida que é nossa morada.

- O espaço para o novo compreende uma certa desadequação dos sujeitos.

- O espaço da telemática elimina interdições, expõe intimidades, dificulta e facilita controles e convívios.

- Os espaços da atualidade, se deixam os sujeitos perdidos, os deixam, também, mais difíceis de serem controlados pelos governos.

- Esses espaços revelam um homem com possibilidades de encontros mais genuínos e, por isso, mais caçado e cassado pelo poder.

\section{Referências bibliográficas}

Aparício A, Bronstein N \& Saal F 1980. Un divan para Antígona, pp.169-189. In N Bronstein (org.). Cincuenta Años del Mal Estar en la Cultura en la Cultura. Ed. Siglo Veinteuno, México.

Argan GC 1964. La mémoire et les rithmes. In Le geste et la parole, vol. II. Bibliothèque Albin Michel Sciene. Paris.

Argan GC 1992. História da Arte como História da Cidade. Martins Fontes, São Paulo.

Argan GC 1999. Clássico Anticlássico: o Renascimento de Brunelischi a Bruegel. Companhia das Letras, São Paulo.

Badiou A 1997. Ética: um Ensaio sobre a Consciência do Mal. Relume Dumará, Rio de Janeiro.

Bandeira M 1986. Bandeira a Vida Inteira. Edições Alumbramento, Rio de Janeiro.

Basaglia F 1985. A Instituição Negada. Edições Graal, Rio de Janeiro.

Benko G 1994. Breve exame do mundo pós-moderno, pp. 247-250. In M Santos, ML Souza \& ML Silveira. Território, Globalização e Fragmentação. Ed. Hucitec/ Ampur. São Paulo.

Boltanski L 1979. As Classes Sociais e o Corpo. Edusp, São Paulo.
Carneiro LC 1992. A ética do desenvolvimento. In MC Leal et al. Saúde, Ambiente e Desenvolvimento. Ed. Hucitec-Abrasco, São Paulo-Rio de Janeiro.

Choay F 1992. O Urbanismo. Ed. Perspectiva, São Paulo.

Cullen G 1968. Townscape. The Architectural Press, Londres.

Freud S 1972. A interpretação dos Sonhos. Obras Completas (O.C.) 5:361-727. 1984. Die Traumdeutung. (1900) Fisher Taschenbuch Verlag, Frankfurt.

Freud S 1974. Mal-Estar na Civilização. (O.C.). Imago Editora Rio de Janeiro. vol 21:75-173. 1948. Das Unbehagen in der Kultur (1930). Gesammelte Werke (G.W.), Imago. Publishing Londres.14:419-506.

Freud S 1974. Sobre o Narcisismo (O.C.) 14:89-119. 1948 Zur Einführung des Narzissmus (1914). G.W. 10:138170.

Freud S 1976. A Negativa (O.C.) 19:290-300.1948. Die Verneinung. (1925) G.W.,13:9-15.

Hartwood LA 1968. Planning for Play. Ed. Thames \& Hudson, Londres.

Heidegger M 1958. Bâtir, habiter, penser, pp. 57-72. In Heidegger M Essais et Conférences. Gallimard, Paris. Heidegger M 1958. La chose. In Heidegger M Essais et Conférences. Gallimard, Paris. 
Heidegger M 1958. “... L'homme habite en poète...”, pp. 70-98. In Heidegger M Essais et Conférences. Gallimard, Paris.

Heidegger M 1990 Die Frage nach der Technik, pp. 87105. In Heidegger M Vorträge und Aufsätze. Neske Pfulligen, Stuttgart.

Leroi GA 1964. Le geste et la parole. In La Memoire et les Rithmes. Bibliothèque Albin Michel Sciene. Paris.

Lorenzo M. Apresentação do livro Clássico Anticlássico: O Renascimento de Brunelischi a Bruegel. Companhia das Letras. São Paulo.

McDougall J 1978. Plaidoyer pour une Certainne Anormalité. Gallimard, Paris.

Merleau Ponty M 1984. A Crise do Entendimento. Coleção Pensadores Abril Cultural, São Paulo.
Sami-Ali M 1974. L’Espace Imaginaire. Gallimard, Paris. Santos M 1993. Metrópole: a força dos fracos é seu tempo lento. Ciência \& Ambiente IV (4):7-12.

Soalheiros, NI 1998. Invenção da Assistência: uma Orientação Ética para a Clínica em Saúde Mental na Rede Pública. Dissertação de mestrado. Escola Nacional de Saúde Pública, Fundação Oswaldo Cruz, Rio de Janeiro.

Valadares JC 1994. Espaço Ambiente e Situação do Sujeito. Tese de doutorado. Escola Nacional de Saúde Pública, Fundação Oswaldo Cruz, Rio de Janeiro.

Winnicott DW 1975. O Brincar e a Realidade. Imago, Rio de Janeiro.

Winnicott DW 1982. O Ambiente e os Processos de Maturação. Artes Médicas, Porto Alegre. 